\title{
UMA NOVA DISCIPLINA: O DIREITO SANITÁRIO
}

\author{
Sueli Gandolfi Dallari*
}

DALLARI, S.G. Uma nova disciplina: o direito sanitário. Rev. Saúde públ., S. Paulo, 22:327-34, 1988.

\begin{abstract}
RESUMO: A reivindicação da saúde como direito tem levado o Estado a assumir responsabilidades crescentes pela promoção, proteção e recuperação da saúde do povo. A atuação do Estado contemporâneo - de Direito - é orientada por normas jurídicas. O conhecimento das normas que regulam a ação estatal no campo da saúde é indispensável ao sanitarista, profissional designado pela sociedade para trabalhar especificamente pela elevação de seu nivel de saúde. Nessa linha, foram analisadas experiências estrangeiras com o ensino do direito sanitário, juntamente com as recomendações dos organismos internacionais de saúde. Conclui-se que a implementação do ensino do direito sanitário, no Brasil, é urgente.
\end{abstract}

UNITERMOS: Direito à saúde. Legislação sanitária. Ética médica. Organização e políticas governamentais.

\section{VARIEDADE DE SIGNIFICADOS}

Modernamente a expressão direito à saúde tem sido empregada referindo-se a situações, algumas vezes, extremamente diferentes. Muito da imprecisão dessa expressão decorre da imprecisão do próprio conceito de saúde. Ainda que se desconsiderem as demais definições de saúde que não aquela proposta pela Organização Mundial de Saúde, observa-se o enorme halo nebuloso que circunda o núcleo básico do conceito. Assim o conceito de saúde não implica apenas a ausência de doença - núcleo básico -, mas também o completo bem estar físico, mental e social - halo nebuloso.

Para que se defina o direito sanitário importa, portanto, que se identifique o conjunto de normas que referem a preocupação principal com a ausência de doenças e com o completo bem-estar físico, mental e social do indivíduo numa comunidade. Tal tarefa, de Hércules, impõe a delimitação de áreas cujos conteúdos muitas vezes se identificam, mas que não se confundem. Assim, exemplificativamente, os textos que regulamentam as profissões médica e paramédica contêm normas que visam prioritariamente proteger, manter ou melhorar a saúde dos indivíduos, semelhantes àquelas contidas nos códigos sanitários. Por outro lado, por exemplo, tais textos abrigam regras sobre o regime fiscal do profissional liberal que nada interessam ao direito sanitário, assim como os códigos de saúde apresentam disposiçס̄es sobre higiene das habitaçôes que não interessam ao direito médico.
Tarefa ainda mais difícil é separar-se as regras de conteúdo especificamente sanitário das demais que visam melhorar a condição social dos indivíduos. Todo o direito, assim chamado, social - como se existisse um direito que não seja social! - baseia-se na definição das necessidades humanas e na existência de pessoas que não dispõem de meios para satisfazê-las. É a lei, então, que irá superar essa barreira prevendo proteção especial para os mais fracos. Ora, o direito sanitário é, sem duvida, parte do direito social, assim como o são, também, o direito do trabalho e da segurança social, por exemplo.

\section{REIVINDICAÇÃO DO DIREITO Ȧ SAÚDE}

A reivindicação do "Direito à Saúde" é moderna, não obstante ela esteja, hoje, agregada ao rol dos "Direitos Humanos", cuja reivindicação é antiga. Imemorial mesmo. Não existe uniformidade na enumeração dos chamados direitos humanos, uma vez que a saúde, por exemplo, só foi incluída no elenco contemporâneo desses direitos. É indispensável, portanto, conhecer-se a evolução da idéia de direitos humanos para que se possa compreender a reivindicação moderna do "Direito à Saúde".

Em todas as épocas da história humana podem se identificar comportamentos de pessoas ou grupos de pessoas em reação à autoridade dos governantes, como fundados na idéia da existência de direitos que pertencem por natureza ao indivíduo, mesmo contra os poderosos de plantão. Ou melhor, nos primórdios dessa his-

* Departamento de Prática de Saúde Pública da Faculdade de Saúde Pública da Universidade de São Paulo - Av. Dr. Arnaldo, 715 - 01255 - São Paulo, SP - Brasil. 
tória, freqüentemente contra os poderosos de plantão pois, apenas em tal situação se reivindicavam direitos humanos. É exemplo muito característico dessa fase histórica a argumentação de Antígona justificando ter dado sepultura a seu irmão contrariando edito de Creonte: “... Nem nas tuas ordens reconheço força que a um mortal permita violar aquelas não-escritas e intangíveis leis dos deuses.", na bela peça de Sófocles ${ }^{13}(\mathrm{p} .35)$.

$\mathrm{Na}$ Idade Média encontra-se o primeiro documento aceito como declaração de direitos: a Magna Carta da Inglaterra. Porque a reivindicação dos direitos humanos é sempre provocada por ameaças a eles, sustentadas pelo poder dos governantes de fato, em 1215 os barões ingleses exigiram que seu rei, "João sem Terra", assinasse o documento que lhes garantia direitos, pela limitação do poder absoluto do monarca. Como Antígona, os barões e prelados ingleses evocavam a "lei da terra" para afirmarem seus direitos. Veja-se a redação do parágrafo 39 da Magna Carta: "Nenhum homem livre podera śer detido ou mantido preso, privado de seus bens, posto fora da lei ou banido, ou de qualquer maneira molestado, e não procederemos contra ele nem o faremos vir, a menos que por julgamento legítimo de seus pares e pela lei da terra". Na Inglaterra, os nobres logo perceberam que a força dos mais fracos está no comprometimento escrito dos mais fortes.

É, porém, no século dezoito que as declarações solenes de direitos ganham universalidade. Pode-se dizer também que elas sofrem pequenas modificações em seu caráter. Pretende-se, especialmente devido à influência do jusnaturalismo "científico", que os direitos declarados sejam direitos de todos os homens, em todas as situações, porque derivam todos do Direito Natural. Note-se que a partir do século dezessete, sobretudo pela influência de Hugo Grócio, o Direito Natural deixa de ser entendido como divino, tendo mesmo Grócio afirmado que ainda que não existisse Deus haveria o Direito Natural porque ele era a "qualidade moral que tornava justo e certo que um homem fizesse ou tivesse algo" (Grotius', p.19). Percebe-se, portanto, que as declarações de direitos do século dezoito pretendiam, em tese, ser exaustivas. Por outro lado, a realidade mostrou que foram novamente os oprimidos que usaram a reivindicação dos direitos humanos contra os opressores. Assim, os ex-colonos ingleses que viviam na América editaram suas declarações de direitos concomitantemente à sua libertação dos colonizadores (Declaração de Direitos da Virginia, de 12 de janeiro de 1776). Do mesmo modo, os burgueses franceses, ao tomarem o po- der político dos nobres, aprovaram sua Declaração dos Direitos do Homem e do Cidadão, em 26 de agosto de 1789.

A industrialização mudou rapidamente a face da terra: criou nova classe social, transferiu o fulcro da vida social para as cidades e aproximou cada vez mais as pessoas por diversos meios de comunicação. As pessoas de sensibilidade perceberam, então, que a afirmação de direitos não garantia a paz social porque a maioria das pessoas não tinha condições para exercer esses direitos. As revoluções socialistas, russa, em 1917 e alemã, em 1919, e especialmente a segunda grande guerra convenceram os relutantes da necessidade do reconhecimento do "direito a gozar dos direitos humanos" para que mesmo os poderosos de plantão pudessem fruí-los. Com efeito, as declarações de direitos do século vinte enumeram alguns direitos ao gozo dos direitos, tais como o direito ao trabalho, ao descanso, a um nível de vida adequado, por exemplo. (Declaração Universal dos Direitos Humanos da Organização das Nações Unidas, artigos 23,24 e 25).

Percebe-se, portanto, que ainda hoje a reivindicação por direitos humanos é arma dos oprimidos contra os opressores mas não se pode deixar de reconhecer que ela só é possível porque abriga uma idéia de direito fundamental, que independe do direito posto. De fato, muitas vezes a reivindicação dos direitos humanos contraria frontalmente o sistema jurídico de um Estado. Por outro lado, em muitos Estados contemporâneos a declaração de direitos é um capítulo de suas Constituições. E essas incoerências entre os direitos humanos e o direito posto pelo Estado dizem respeito tanto àqueles direitos considerados políticos, que privilegiam a liberdade, como aos direitos econômicos, o "direito de ter direitos", relacionados essencialmente com a igualdade dos seres humanos. E ainda aqui se pode definir a identidade da idéia de direito fundamental que baseia tais reivindicaçð̃es de direitos humanos. De fato, pode-se afirmar que existe uma idéia de direito humano em toda a sociedade, mais que ela perpassa cada organização social e cuja essência é a dignidade humana. Essa dignidade pode ser aviltada tanto por poderosos que a dominem politicamente como por poderosos que a explorem economicamente. Em ambos os casos a reivindicação por direitos humanos será a arma do oprimido contra o opressor.

A crescente complexidade da vida social neste século acarretou a reivindicação por direitos complexos. A garantia da dignidade humana exige contemporaneamente mecanismos complexos de atuação. Para sua efetivação cobra-se 
do poder social tanto sua abstenção quanto sua atuação para garantir o mesmo direito. Assim, por exemplo, a liberdade de expressão escrita requer a intervenção do Estado para impedir que apenas os grandes impérios financeiros possuam meios de expressão escrita. Por outro lado, para garantir o direito dos leitores é necessário que o Estado se abstenha a respeito do que é exprimido, permitindo que as idéias circulem livremente. Entretanto, existem os chamados delitos de imprensa, sobre os quais há consenso quanto à conveniência de vigilância exercida pelo Estado. Conclui-se, portanto, que apenas a participação do povo numa democracia permite a definição dos direitos humanos que vigoram em determinada sociedade. Tinham razão os revolucionários franceses de 1789 ao colocarem no preâmbulo de sua Declaração de Direitos do Homem e do Cidadão que "a ignorância, o esquecimento ou o desprezo dos direitos do homem são as únicas causas das infelicidades públicas e da corrupção dos governos", isso porque a curiosidade constante e o respeito permanente a esses direitos são condiçōes da democracia.

$\mathrm{O}$ direito à saúde tem história semelhante à dos demais direitos humanos. Documentos da Antiguidade possuem entremeadas com preceitos morais e religiosos, regras que implicam o reconhecimento da saúde como indispensável à dignidade humana. Existem normas relativas ao zêlo exigido do profissional que cuida da doença no Código de Hamurabi, direito babilônico e no código de Manu, direito hindu, por exemplo*.

Durante a Idade Média, com o predomínio da religião, sendo a doença castigo divino, apenas vozes isoladas e sem repercussão advogaram o direito à saúde, que permaneceu adormecido até o advento do industrialismo. A partir de então define-se o direito à saúde com as características modernas do instituto.

Inúmeros trabalhos relatam a evolução das formas de cuidados sanitários ao longo das épocas históricas. Todos são concordes ao afirmar que até o período industrial a única preocupação era afastar o doente, tanto para impedir a possível visão desagradável como, mais tarde, para impedir o contágio. E é importante lembrar que em todos os casos sempre foi a própria comunidade que se organizou para criar e manter esses hospitais, recolhimentos de doentes e miseráveis. A revolução industrial alterou radicalmente esse comportamento.

A urbanização, conseqüência imediata da industrialização no século dezenove, foi, junta- mente com o próprio desenvolvimento do processo industrial, causa da assunção pelo Estado da responsabilidade pela saúde do povo. De fato, é inestimável o papel da proximidade espacial na organização das reivindicações operárias. Vivendo nas cidades, relativamente próximos, portanto, dos industriais, os operários passam a almejar padrão de vida semelhante. Conscientes de sua força devida à quantidade deles, organizam-se para reivindicar tal padrão. Entretanto, cedo o empresariado percebeu que precisava manter os operários saudáveis para que sua linha de montagem não sofresse interrupção. Percebeu também que, devido à proximidade espacial das habitaçð̃es operárias, ele poderia ser contaminado pelas doenças de seus empregados. Tais conclusōes induziram outra: - Estado deve se responsabilizar pela saúde do povo. É claro que para ele - empresário - o povo era apenas os operários uma vez que os cuidados individuais de saúde eram facilmente financiados pelos industriais. Por outro lado, eles faziam também parte do povo quando exigiam que o Estado garantisse a ausência de doenças contaminantes em seu meio ambiente. $\mathrm{E}$, como o Estado liberal era instrumento do empresariado nessa fase da sociedade industrial, foi relativamente fácil a transferência das reivindicações operárias de melhores cuidados sanitários dos empresários para o Estado.

O processo contínuo de organização do operariado promovido a partir da conscientização de suas condições de trabalho e facilitado pelo desenvolvimento dos meios de comunicação levou-o a reivindicar que o Estado, idealmente acima dos interesses dos industriais, se responsabilizasse pela fiscalização das condições de saúde no trabalho. $O$ evoluir desse processo acabou conscientizando todo o povo, especialmente a partir da Segunda Guerra Mundial, para a necessidade de responsabilização do Estado pela saúde da população, agora compreendida não apenas como a ausência de doenças. Com efeito, o completo bem estar físico, mental e social não pode ser conseguido apenas com atitudes isoladas. Ninguém tem condições de alcançar somente com seus próprios meios tal estado de bem-estar na sociedade moderna.

\section{O DIREITO À SAÚDE}

Tendo o Estado assumido inicialmente a prestação de cuidados de saúde como prestação de um serviço público, é fácil supor-se a grande quantidade de textos legais que regem a execu-

* Veja -se os artigos 218 e 219 do código de Hamurabi e o artigo 695 do código de Manu. 
ção desse serviço. Isso porque toda atividade administrativa do Estado moderno é realizada sob a lei, podendo-se prontamente concordar com Seabra Fagundes ${ }^{12}$, quando afirma que "administrar (na área pública) é aplicar a lei de ofício". De fato, sendo a administração pública limitada pelos principios da supremacia do interesse público sobre o privado e pela indisponibilidade dos interesses públicos e sendo o interesse público definido pela própria sociedade, o administrador não pode trabalhar senão com o conhecimento do interesse público que ele deve realizar. Ora, o interesse público no moderno Estado de Direito, porque sob leis, é definido pela sociedade em forma de textos legislativos que representam a vontade geral dessa sociedade. A função executiva foi determinada pela própria sociedade para realizar os objetivos definidos nas normas legisladas. Assim, o administrador público sempre age guiado por uma série de leis orientadas para o perfazimento do interesse público que, como se viu no que respeita aos cuidados sanitários, delimitam os objetivos da atuação do Estado na área da saúde e os meios a serem empregados para atingí-los.

Contudo, atualmente, a saúde não tem apenas um aspecto individual que respeita apenas a pessoa. Não basta que sejam colocados à disposição dos indivíduos todos os meios para promoção, manutenção ou recuperação da saúde para que o Estado responda satisfatoriamente à obrigação de garantir a saúde do povo. Hoje os Estados são, em sua maioria, forçados por disposição constitucional a proteger a saúde contra todos os perigos. Até mesmo contra a irresponsabilidade de seus próprios cidadãos. A saúde "pública" tem um caráter coletivo. O Estado contemporâneo controla o comportamento dos indivíduos no intuito de impedir-lhes qualquer ação nociva à saúde de todo o povo. $\mathrm{E}$ o faz por meio de leis. É a própria sociedade por decorrência lógica que define quais são esses comportamentos nocivos e determina que eles sejam evitados, que seja punido o infrator e qual a pena que deve ser-lhe aplicada. Tal atividade social é expressa em leis que a administração pública deve cumprir e fazer cumprir.

O mundo contemporâneo, com o grande desenvolvimento dos meios de comunicação evidenciou que o nível de saúde de um povo é dependente do seu nível de desenvolvimento sócio-econômico e cultural. De fato, não basta a existência de serviços destinados à promoção, proteção e recuperação sanitária adequados e em número suficiente, nem a existência de normas legais prevendo todas as hipóteses de agravos à saúde pública, se o Estado não tiver atin- gido um nível tal de desenvolvimento sócio-econômico e cultural que lhe permita dispor de todos os recursos técnicos existentes, atender a todas as necessidades de infra-estrutura e possuir uma população educada para a saúde. Assim, o Estado subdesenvolvido que não possui todos os recursos técnicos conhecidos para o tratamento de certas patologias, que não dispõe de meios econômicos para promover o saneamento am. biental ou que não educou sua população para a saúde, não pode atingir o mesmo nivel sanitário daquele desenvolvido que já emprega tais recursos sócio-econômicos e culturais.

Ora, são também textos legais que orientam a ação do Estado para a realização do desenvolvimento sócio-econômico e cultural. Conceitualmente, a sociedade define os rumos que devem ser seguidos para alcançá-lo, estabelecendo normas jurídicas cuja obediência é obrigatória para a administração pública. E como a saúde depende também desse nível de desenvolvimento, as disposições legais que lhe interessam estão contidas em tais planos de desenvolvimento do Estado.

O direito da saúde pública é, portanto, parte do direito administrativo, ou uma aplicação especializada do direito administrativo. É parte do direito administrativo porque refere sempre atuaçðes estatais orientadas o mais exaustivamente possível, pela própria sociedade por meio do aparelho legislativo do Estado. Em termos práticos, ao direito da saúde pública assenta perfeitamente o rótulo de direito administrativo porque se trata de disciplina normativa que se caracteriza pelo preenchimento daqueles princípios básicos da supremacia do interesse público sobre o particular e da indisponibilidade do interesse público (Mello7, p.5). Entretanto, a referência ao direito administrativo não é suficiente, uma vez que na aplicação peculiariza-se o direito da saúde pública: ora são as atuações decorrentes do poder de polícia, ora a prestação de serviço público, ora, ainda, um imbricamento de ambos, como no caso da vacinação obrigatória realizada pelos serviços de saúde pública, que visam, principal ou exclusivamente, promover, proteger ou recuperar a saúde do povo.

\section{O SANITARISTA E O DIREITO SANITÁRIO}

O sanitarista é o profissional designado pela sociedade para trabalhar especificamente pela elevação de seu nível de saúde. Ele é formado para conhecer todas as técnicas que permitam melhorar tal nível e a sociedade espera dele não só que as aplique mas, também, que a informe 
sobre os comportamentos que favorecem ou prejudicam o alcance daquele desiderato.

Já se verificou que no Estado contemporâneo a vontade geral da sociedade revela-se por meio das normas editadas por seu poder legislativo, composto de representantes do povo. Para que as regras referentes à saúde do povo reflitam realmente a vontade geral dessa sociedade é necessário que ela conheça qual sua situação sanitária e quais os meios de que ela pode dispor para alterá-la para, então, determinar quais os objetivos e os meios de atingí-los. E foi, também, para dispor dessas informações que permitem decisão segura que a sociedade formou o sanitarista. Espera-se, portanto, no Estado contemporâneo, que o sanitarista oriente a feitura das leis que conformam o direito da saúde pública.

Mas isto não é tudo. O mister do sanitarista corresponde sempre à execução de um serviço público. Ora, o servidor público é um funcionário da administração estatal e está, portanto, cingido aos princípios que orientam toda atividade administrativa do Estado: a administração é a atividade de quem não é senhor absoluto, deve realizar-se sempre sob a lei, conforme afirma Cirne Lima ${ }^{2}$. Fica evidente, então, que o sanitarista deve, necessariamente, conhecer as normas que compõem o direito da saúde pública para que ele possa cumprir adequadamente sua missão de executor da vontade geral da sociedade.

A reivindicação do direito à saúde como um dos direitos humanos fundamentais criou para o sanitarista a necessidade de conhecer as formas de expressão e de realização de tais direitos no mundo contemporâneo. Apenas compreendendo o processo de documentação escrita do reconhecimento de direito aos oprimidos é que o sanitarista poderá orientar as reivindicaçōes sanitárias, encaminhando-as para a realização, propondo sua transformação em normas de direito da saúde pública.

Assim, é óbvio, que ao verdadeiro sanitarista interessa o conhecimento do processo de definição dos direitos humanos em geral e especialmente do direito à saúde, assim como de todo o processo legislativo e do conjunto das leis contidas no direito da saúde pública, tanto em nível nacional como internacional.

\section{EXPERIÊNCIAS ESTRANGEIRAS COM O ENSINO DO DIREITO SANITÁRIO}

Há muito a Organização Mundial de Saúde se interessa pelo direito e a legislação sanitária, tanto no plano internacional como nos diferentes Estados. Todavia, o desenvolvimento contemporâneo desse interesse é recente. Apenas em 1977, durante a 30. Assembléia Mundial de Saúde, foi tomada a Resolução WHA 30.44 15 que, "reconhecendo que uma legislação sanitária adaptada aos imperativos nacionais tende a proteger e melhorar a saúde do indivíduo e da coletividade", "pede ao Diretor Geral que reforce o programa da OMS no campo da legislação sanitária para ajudar os Estados membros.... estude e coloque em ação os melhores meios de difusão da informação legislativa nos Estados membros objetivando inspirar a formulação ou a revisão de textos de lei relativos à saúde". Tal Resolução provocou a manifestação da 33. Assembléia Mundial de Saúde 16 (1980) que, durante sua $17^{\text {a }}$. Sessão Plenária manifestou-se sobre o "rapport" do Diretor Geral, nos seguintes termos: "Notando que uma legislação sanitária apropriada é um elemento essencial dos sistemas de serviços de saúde e de higiene do meio ambiente", "pede ao Diretor Geral.. . a elaboração de um programa detalhado de cooperação técnica e de transferência de informação em matéria de legislação sanitária".

O Escritório Regional para a Europa, da OMS, criou, em conseqüência dessas recomendações, um Comitê Consultivo de Legislação Sanitária. Em sua reunião de junho de 1981, tal Comitê considerou que "para atuar a política de saúde que deseja, um governo pode apoiar-se... na legislação e regulamentação propriamente ditas" (Auby', p.5). E, por tais motivos, o Escritório Regional para a Euro$\mathrm{pa} /$ OMS realizou uma enquete para fundamentar um estudo com os seguintes objetivos: "rever e analisar a situação européia concernente aos programas e meios de formação em direito e legislação sanitária; comparar a situação nos diferentes países da Europa com relação às instituições concernentes e os conteúdos dos programas de ensino; indicar as tendências atuais na Europa quanto a esse ensino; formular as recomendaçōes para encorajar tal ensino e promover seu reconhecimento e sua utilização ótima pelos Estados membros" (Auby', p.7). Os resultados dessa enquete apontam a existência de inúmeros cursos, tanto em escolas de formação médica, como jurídicas e mesmo em institutos de nível superior agregados ou não às Universidades.

O direito sanitário é ensinado em todos os Estados europeus. Cumpre destacar, especialmente, seu ensino em pós-graduação, na Itália (Faculdade de Direito de Bologna) e na França (Universidades de Bordeaux I, Paris Sud, Lyon I).

Em Bologna, a Facoltá de Giurisprudenza (Universitá degli studi di Bologna) organizou 
em 1962 um curso de aperfeiçoamento em direito sanitário, que, em 1979, originou a Scuola de Perfezionamento in Diritto Sanitário, agregada à Faculdade de Direito. Esse curso, realizado em dois anos, com um mínimo de 110 horas, oferece um diploma de aperfeiçoamento em direito sanitário, para graduados em várias áreas (direito, ciência política, economia, medicina, veterinária, farmácia, engenharia....), desejosos de receber formação especializada em direito sanitário. Em 1981 e 1982, as disciplinas obrigatórias $(80 \mathrm{~h})$ eram as seguintes: Direito Constitucional e Saúde Pública; Direito Administrativo e Saúde Pública; Organização Sanitária Italiana; Organização Sanitária Internacional; Polícia Sanitária; Profissões Sanitárias e Responsabilidade Penal Sanitária. No segundo ano do curso o aluno pode escolher 5 disciplinas (30h) entre as seguintes: Justiça Administrativa; Proteção Contra Radiaçōes Ionizantes; Legislação de Alimentos; Sociologia Sanitária; Programa Sanitário; Estatísticas Sanitárias; Urbanística Hospitalar; Higiene da Habitação; Transplante de Órgãos; Estupefacientes; Tratamento Sanitário; Legislação Sanitária Escolar e Esportiva; Legislação Sanitária Militar, Marítima e Aérea.

Na França, o Centro de Direito Sanitário, da Universidade de Bordeaux I, permite aos titulares de mestrado em direito público ou privado ou graduados em medicina, farmácia, odontologia... adquirirem o diploma de estudos especializados em Direito Sanitário que lhes dá o direito de, após dois anos, obter o grau de Doutor, pela redação de uma tese. O programa de estudos dura um ano (145 horas) e contém as seguintes disciplinas: Direito Médico Geral; Direito das Profissões Paramédicas; Direito Farmacêutico; Direito da Consumação; Direito Internacional da Saúde e da Higiene; Direito da Segurança e da Assistência Social.

Nas Américas, a Universidade de Columbia, nos Estados Unidos, uma das três primeiras escolas de saúde pública no mundo, mantém regularmente cursos de legislação de saúde pública como disciplina introdutória da saúde pública, cursos sobre os aspectos legais da administração dos serviços de saúde, sobre regulamentação governamental dos cuidados de saúde e sobre os aspectos legais da enfermagem para a administração sanitária e curso de legislação e política populacional como disciplina de demografia e saúde familiar.

Os programas dos cursos que privilegiam o estudo do direito da saúde pública na Universidade de Columbia, abordam desde os direitos humanos e aspectos legais do aborto, da esterilização compulsória e do acesso à contracepção
- em legislação e política populacional - até a análise legal do estado atual e das tendências observáveis da legislação das organizaçōes de prestação de cuidados de saúde no seu relacionamento com hospitais gerais de curta permanência - em regulamentação legal governamental dos cuidados de saúde - por exemplo"1.

As escolas de saúde pública estadunidenses, interessadas em adaptar seus programas de formação de administradores de saúde, têm enfatizado a importância do conhecimento do direito da saúde pública em tal formação. Assim, a Escola de Saúde Pública da Universidade de Washington estabeleceu uma unidade de política sanitária, em conjunto com o departamento legislativo em Olympia, com o duplo objetivo de "melhorar a legislação nova e a administração da legislação existente enquanto melhora as condições de treinamento para os alunos de graduação" (Remington ${ }^{10}$, p.336). Comportamentos semelhantes devem ter sido influenciados pelo relatório da "Comissão sobre Educação para Administradores Sanitários"' (Kellogg Foundation ${ }^{14}$, 1974) que incluiu como o primeiro elemento chave para a gerência administrativa em saúde e cuidados médicos o conhecimento da "legislação que - envolve todos os tipos de instituições, agências e programas de saúde e de cuidados medicos". Tambem a lei 94-484, de 1976, conhecida como "The health profession educational assistance act", influenciada por aquele relatório, orientou as iniciativas do governo federal para incluirem entre seus objetivos específicos "o apoio ao desenvolvimento ou expansão do conteúdo ou linha mestra de curriculum especializado em política e legislação (Hatch e Holland ${ }^{6}$, p.359). Os especialistas do Escritório de Recursos Humanos para a Saúde do Departamento de Saúde, Educação e Bem-estar dos Estados Unidos da América, (Hatch e Holland 6 , p.357) reafirmaram tal necessidade esclarecendo que as áreas curriculares que recebem hoje ênfase especial, na formação de administradores sanitários naquele país, incluem a política pública e a legislação.

$O$ reconhecimento por todo continente americano da necessidade e importância do elemento legal em matéria de saúde, tradicionalmente pobre, começa a ganhar impulso com a próxima publicação do trabalho "Saúde e Constituição". De fato, a Organização Panamericana de Saúde (OPS), por meio de seu Escritório para Assuntos Legais, pretende que esse trabalho inovador contribua para a sistematização do "direito da saúde como disciplina, da qual a legislação sanitária, tradicionalmente a ela associada, é um componente"'. O documento da OPS que serve de roteiro para a elaboração do 
trabalho, em cada Estado americano, citado por Fuenzalida-Puelma e col. ${ }^{4}$, refere Resolu. ção WHA 30.44, da Assembléia Mundial da Saúde ${ }^{15}$.

\section{O ENSINO DO DIREITO SANITÁRIO NO BRASIL}

A compreensão da evolução conceitual da saúde e do direito a ela relacionado evidencia que a adequação às recomendações dos organismos internacionais interessados na saúde se dará com a ampliação da matéria legal a ser ensinada para os trabalhadores na área da saúde. De fato, o ensino do direito sanitário não deriva apenas da lei, mas dos demais atos jurídicos (constituição, tratados, regulamentos) e, especialmente das decisões jurisprudenciais. $\mathrm{O}$ direito escrito não é, porém, a única fonte de direito sanitário, devendo-se especial atenção aos princípios gerais não escritos e mesmo ao costume.

A matéria do direito sanitário não pode também restringir-se ao jurídico, uma vez que a regra de direito deriva da realidade social e nela encontra as condições de eficácia. Não se pode ensinar direito abstraindo-o da moral e, a ambos, do social. Deve-se, aqui, advertir para a virtual incapacidade do profissional do direito de dominar o conhecimento relativo à moral e à sociologia. Fato natural que requer o auxílio de filósofos e sociólogos.

O ensino do direito sanitário, compreendida a evolução conceitual da saúde, implicará seu exame enquanto direito individual, enfatizando, por exemplo, as regras do contrato entre o médico e o paciente, não se esquecendo, contudo, de examiná-la enquanto direito coletivo. Dever-se-á, portanto, estudar as normas que disciplinam a proteção da saúde da comunidade, assim como, as medidas de caráter particular que possibilitam tal proteção (a vacinação, o isolamento, o tratamento compulsórios). Dada a limitação representada pelo nível de desenvolvimento sócio-econômico e cultural do Estado para o direito à saúde, o direito sanitário deve estudar, também, todas as normas jurídicas de planejamento da saúde, condicionantes importantes do nível de saúde de qualquer Estado contemporâneo.

Conclui-se, em um exame superficial, que o ensino do direito sanitário deve, portanto, incluir áreas como: Introdução à Filosofia e Sociologia do Direito Sanitário; Organização Jurídica da Administração Sanitária; Direito Penal Sanitário; Direito dos Serviços de Saúde; Direito do Planejamento Sanitário; Direito Previdenciário Sanitário; Direito Internacional Sanitário; Ética Sanitária; Polícia Sanitária; e Direito Sanitário Comparado.

A simples enumeração dos temas sugere a necessidade de encontrar professores com experiência em saúde e direito para desenvolverem adequadamente tal ensino. No Brasil, esse profissional ainda é raro no mercado, todavia urge formá-lo. Os sanitaristas já estão interessados pelas questões jurídicas relacionadas à sua prática profissional, como o provam as citadas resoluções dos organismos sanitários internacionais.

É de justiça louvar-se o pioneirismo de dois insignes juristas brasileiros que vêm se dedicando ao estudo do direito sanitário: Hélio Pereira Dias, autor do clássico "Direito de Saúde"'3 e César Luiz Pasold, cujos trabalhos para obtenção dos títulos de mestre em saúde públi$\mathrm{Ca}^{8}$ e doutor em direito ${ }^{y}$ são exemplos de pesquisa acadêmica. Cumpre agora despertar o interesse de outros juristas brasileiros pelo vasto campo de estudo que representa o direito sanitário. Essa será a primeira etapa na formação de um novo profissional que alinhe seus conhecimentos, com prioridade sanitários ou jurídicos, aos derivados do estudo do Direito ou da Saúde, respectivamente.

A existência de um campo que pode ser caracterizado como do Direito Sanitário é um fato. Todas as instituições de ensino que formam algum tipo de profissional para a área da saúde ou do direito devem assumir a responsabilidade de contribuir para o preparo adequado de profissional competente para atuar nesse campo - Direito Sanitário - sob pena de serem atropeladas pela História. 
DALlARI, S.G. [A new (Brazilian) academic discipline: health law]. Rev. Saúde públ., S. Paulo, 22:327-34, 1988.

\begin{abstract}
The demand for health seen as the citizen's right, has led the State to accept increasing responsabilities regarding the health of the people, as evidenced by policies of health promotion, protection and recovery. The activity of a modern State ("State of law") is exercised according to juridical principles. It is highly advisable, therefail, that health workers-those professionals that society has appointed to work on its behalf for the raising of its health levels should have knowledge of the rules which guide the State's performance in the health area. Thus, foreign experiences in teaching health law as well as the recommendations of International Health Agencies, analysed in this paper, lead us to conclude that the teaching of health law is a must among the Brazilian academic priorities.
\end{abstract}

UNITERMS: Health rights. Legislation health. Ethics, medical. Government policies and organization.

\title{
REFERÊNCIAS BIBLIOGRÁFICAS
}

1. AUBY, J.M. Legislation sanitaire: programmes et moyens de formation en Europe. Paris, Masson, 1984.

2. CIRNE LIMA, R. Principios de direito administrativo. Porto Alegre, Sulina, 1954.

3. DIAS, H.P. Direito de saúde. Rio de Janeiro, ESESP, 1979.

4. FUENZALIDA-PUELMA, H.L. et al. Health and national constitutions: a survey in the Region of Americas. Int. Dig. Hith Legis., 37:673-5, 1986.

5. GROTIUS, H. The rights of war and peace. London, M. Walter Dunne, 1901.

6. HATCH, T.D. \& HOLLAND, W.J. Education for health management: a federal perspective. In: Levey, S. \& McCarthy, T. Health management for tomorrow. Philadelphia, J.B. Lippincolt, 1980.

7. MELLO, C.A.B. Elementos de direito administrativo. São Paulo, Revista dos Tribunais 1980. p. 5.

8. PASOLD, C.L. Estudo evolutivo da legislação sanitá. ria catarinense e suas repercussões na estrutura dos serviços de saúde pública de Santa Catarina. São Paulo, 1978. [Dissertação de Mestrado - Faculdade de Saúde Pública da USP].

9. PASOLD, C.L. Da função social do Estado contemporâneo ao estudo político e jurídico de um dos seus segmentos: a saúde pública. São Paulo, 1983. [Tese de Doutorado - Faculdade de Direito da USP].

10. REMINGTON, R.D. Planning the curriculum for health managers in schools of public health. In: Le- vey, S. \& McCarthy, T. Health management for tomorrow. Philadelphia, J.B. Lippincolt, 1980.

11. SCHOOL of Public Health: 1984-86. Columbia Univ. Bul., 18(5), 1984.

12. SEARA FAGUNDES, M.S. Controle dos atos administrativos pelo poder jurídico. Rio de Janeiro, Forense, 1957, p. 17

13. SÓFOCLES. A Antigone. São Paulo, Alarico, 1952.

14. W.K. KELLOGG FOUNDATION. Summary and the report of the Comission on Educalion for Health Administration. Ann Arbor, Michigan, Health Administration Press, 1974.

15. WORLD HEALTH ASSEMBLY, $30^{\text {th }}$, Geneva, May, 1977. [Resolution] WHA 30.44. In: World Health Organization. Handbook of resolution and decisions of the World Health Assembly and the Executive Board: 1973-1984. Geneva, 1985. v.2.

16. WORLD HEALTH ASSEMBLY, $33^{\text {rd }}$, Geneva, May, 1980. [Resolution] WHA 33/17. In: World Health Organization. Handbook of resolution and decisions of the World Health Assembly and the Executive Board: 1973-1984. Geneva, 1985. v.2.

Recebido para publicação em 4/8/1987 Reapresentado em 3/3/1988 Aprovado para publicação em 7/3/1988 